\author{
Lina Alves Arruda
}

Universidade Estadual de Campinas

\author{
Maria de Fátima Morethy Couto \\ Universidade Estadual de Campinas
}

\title{
Ativismo artístico: engajamento político e questões de gênero na obra de Barbara Kruger
}

\begin{abstract}
Resumo: O presente artigo introduz e contextualiza as primeiras manifestações feministas que compuseram o panorama artístico do final da década de 1960 até 1980. São analisadas as circunstâncias históricas (incluindo a história da arte) que facilitaram a ponte entre as esferas da arte e da política, bem como os problemas formais e estéticos que a prática artística ativista apresentou e sua recepção como movimento. Para tanto, nos basearemos no trabalho da artista norte-americana Barbara Kruger, que produziu obras fundamentais para a consolidação da arte feminista, abordando criticamente uma ampla variedade de temas relacionados à mulher (violência, aborto, identidade, papel social, estética). O conteúdo das obras de Kruger está em sintonia com importantes circunstâncias políticas e temas sociais contemporâneos à sua produção e estabelece relação direta com teorias feministas da época, permitindo uma análise do contexto artístico e sócio-político do período.
\end{abstract}

Palavras-chave: Barbara Kruger; arte engajada; feminismo; arte contemporânea.

Copyright (c) 2011 by Revista Estudos Feministas.

\section{Introdução}

A obra da artista norte-americana Barbara Kruger (1945-), apesar de extensa e diversificada, possui grande coerência e unidade. Suas composições, de forte identidade visual, originam-se da apropriação de imagens fotográficas (geralmente retiradas de comerciais de revistas e jornais) em preto e branco e da sobreposição de textos de linguagem simples e direta, mas cuja mensagem subverte o sentido inicial da imagem. Abordando uma variedade de temas como consumismo, estética, questões de gênero, política e relações de poder no relacionamento social, a artista constrói um meio eficaz de divulgar seus ideais e 
${ }^{1}$ A Mary Boone Gallery organizou em novembro de 2007 uma exposição da série Picture/ Readings (1976), que formava a primeira produção artística de Barbara Kruger. Os trabalhos expostos também eram elaborados com textos e imagens fotográficas, no entanto continham uma linguagem muito diferente da produção mais conhecida da artista, caracterizando-se como um presságio à obra que seria criada posteriormente. opiniões, meio este dotado, geralmente, de forte teor crítico, o que atribui a seu trabalho um valor além do contemplativo. Sua obra, por conter aspectos irônicos e incisivos e por abordar temáticas sociais, que são centrais da arte contemporânea, como a das minorias (raça, gênero e classe), empreende uma crítica aos valores da sociedade norte-americana.

O público-alvo do trabalho de Barbara Kruger não se restringe ao das galerias e museus de arte, uma vez que suas obras são expostas fora de locais convencionais, principalmente em contextos urbanos, o que lhes confere um caráter público. A organização compositiva produz uma unidade que adere facilmente aos suportes urbanos de exposição (outdoors, pôsteres produzidos em massa, sacolas de compras), pois possui grande semelhança técnica e visual com imagens produzidas pelas mídias de massas.

É importante mencionar que a linguagem gráfica e a organização formal das obras advêm do campo da publicidade e da propaganda. Esse aspecto é normalmente relacionado à sua formação como designer e artista (respectivamente pela Parsons School of Design e Escola de Artes Visuais da Universidade Syracuse), bem como à sua atuação profissional em editoras de revistas norte-americanas como Mademoiselle Magazine, Condé Nast Publications, Aperture e House and Garden.

Apesar de ter exposto pela primeira vez em 1973 na Whitney Biennial de Nova York, as obras pelas quais Barbara Kruger é conhecida atualmente, ou seja, as que impulsionaram sua carreira como artista visual, foram as serigrafias sobre vinil elaboradas no inicio da década de 1980. Essa série integrou parte das primeiras exposições individuais de Barbara Kruger em Nova York, Califórnia, Paris e Londres, inserindo a artista no circuito artístico internacional.

Atualmente, tanto a produção recente de Barbara Kruger (instalações em grande escala compostas por fotografia, projeções de vídeo e aplicações de frases) como também seus primeiros trabalhos têm lugar de destaque no mercado artístico atual e nas instituições de arte: ao mesmo tempo que galerias renomadas como a Mary Boone Gallery organizam mostras de sua produção recente e antiga, acervos renomados (por exemplo, a coleção do MoMA) possuem originais de séries que consolidaram Barbara Kruger como importante artista contemporânea.

\section{Arte engajada: a inserção das questões de gênero no campo artístico}

Acerca da temática de gênero, a obra de Barbara Kruger é extensa e abrange questões como a discriminação 
2 LIPPARD, 1995.

${ }^{3}$ COITINGHAM, 2000, p. 119. sexual, direitos reprodutivos da mulher, estética, identidade, representação feminina e relações sexistas de opressão e poder. Pode-se dizer que Barbara Kruger é uma das artistas que se encaixam com perfeição em uma afirmação feita por Lucy Lippard em um ensaio sobre feminismo e arte, no qual ela diz que as artistas feministas, através de suas obras, não têm a pretensão de se expressarem somente como indivíduos, mas sim como membros de uma unidade maior. ${ }^{2}$ Ou seja, as obras de Barbara Kruger refletem a sua consciência política, interligada ao que significa ser uma mulher em uma sociedade machista.

O surgimento da preocupação com as questões das minorias foi potencializado por fatores de ordem social e política após a Segunda Guerra Mundial (1939-1945). Nesse contexto, as primeiras ideias referentes a classe, raça e gênero surgiram em debates e publicações como o livro $O$ segundo sexo (1949) de Simone de Beauvoir, cujo conteúdo serviu como base para o desenvolvimento do novo feminismo. A conscientização social desencadeada nesse contexto se fortaleceu na década de 1960, que é marcada pelas mudanças drásticas na consciência popular europeia e norte-americana e pela presença de um sentimento coletivo de revolução.

As manifestações organizadas nessa época rejeitavam os princípios conservadores norte-americanos e europeus, como valores patriarcais e familiares, racismo, hegemonia de classes, homofobia, capitalismo etc. Essas mobilizações não se ativeram ao âmbito político (protestos e exigências de alterações legislativas); englobaram também diversos setores da cultura, principalmente a literatura, a música e as artes visuais.

Segundo Laura Cottingham, ${ }^{3}$ o câmbio na consciência coletiva coincidiu com uma mudança na produção artística dessas sociedades: trata-se de um momento que propiciou rupturas dos paradigmas artísticos que prevaleciam até então, entre eles, a ideia de arte moderna. Segundo a autora, o minimalismo e a arte conceitual, apesar de não possuírem grandes semelhanças técnicas ou temáticas com a produção de arte feminista, foram movimentos responsáveis pela construção de uma base fundamental para as práticas contemporâneas, como, por exemplo, a elaboração do conceito de que a produção artística deve estar diretamente relacionada à vida.

Uma das características centrais da arte moderna e das vanguardas era a criação de um domínio específico da arte (com ênfase na pintura), que não interagia e não contribuía diretamente com outras áreas de atuação humanas. Os artistas modernos possuíam um argumento individualista com relação ao motivo de fazer arte (arte por 
${ }^{4}$ GABLIK, 2004, p. 24. Tradução nossa, assim como a tradução das demais citações no texto.

${ }^{5}$ LIPPARD, 1995, p. 134. arte) e defendiam a sua 'inutilidade' dentro dos valores sociais e do capitalismo.

Tais características modernistas foram contestadas pela tendência de aproximação entre arte e vida (sociedade/cultura/coletivo), amparada por teorias marxistas. Como observado por Suzi Gablik, "A estética marxista exige que a arte reproduza as relações sociais, e nos ajude a reconhecer e a mudar a realidade social. A arte [...] deve contar com um público mais amplo, e emitir um juízo crítico sobre os fenômenos da vida. Sua temática deve ser o mundo social". ${ }^{4}$ Dentro dessa abordagem, Lucy Lippard (crítica de arte com enfoques marxistas e feministas) também ataca o formalismo e enfatiza a necessidade de a arte transmitir uma mensagem: "Eu gostaria que todos os artistas, seja qual fosse sua arte, fossem responsáveis desde um ponto de vista social", afirma. ${ }^{5}$

A valorização de práticas artísticas que expressassem consciência com relação às estruturas e valores sociais, políticos e coletivos era circunstancialmente ideal para a produção de arte engajada feminista, que criticava o sistema patriarcal político e social.

No final da década de 1960 e começo de 1970, contradizendo as teorias de Clement Greenberg, que defendiam a pureza da produção artística e estabeleciam diretrizes e áreas específicas de competência única e própria da natureza de cada meio artístico (pintura, fotografia etc.), muitos artistas se voltaram às artes visuais através de outros paradigmas culturais, como teatro e dança (no caso da performance), da mesma maneira que muitas das artistas associadas ao movimento feminista se voltaram à arte por meio do ativismo político.

Os temas por elas abordados coincidiram com as reivindicações da segunda onda do feminismo, que introduziu uma gama mais ampla de questões: além da luta pela igualdade entre gêneros no âmbito constitucional, artistas feministas se centraram em temas específicos da mulher dentro da sociedade patriarcal (comportamento, estereótipo, papel social e valores familiares, sexualidade, direitos reprodutivos etc.).

Na análise de Laura Cottingham, as primeiras produções artísticas feministas tiveram necessariamente que se servir de simbologia pertencente ao sistema patriarcal e que operar dentro de seus códigos preestabelecidos (reproduzindo a sua linguagem) para abordar a temática de gênero; afinal, a representação de um sistema distinto e desvinculado do patriarcado (um suposto matriarcado ou simplesmente a ideia de libertação da mulher de uma estrutura machista) era inconcebível tanto no âmbito artístico como no social: "Era impossível que mulheres artistas 
${ }^{\circ}$ COTTINGHAM, 2000, p. 126.

7 COTTINGHAM, 2000, p. 130. simplesmente estalassem os dedos e eliminassem o sistema pensado, as convenções representativas e as pressuposições discursivas que circunscreviam negativamente a imagem feminina, assim como era impossível que ativistas feministas estalassem os dedos e criassem um estado feminista prómulher imediato". 6

As primeiras obras feministas, além de enfrentarem dificuldades de aceitação do conteúdo que transmitiam, também traziam problemas de interpretação: as representações do mundo feminino produziam uma ambiguidade que oscilava entre o reforço desses valores e sua crítica ou subversão, pois muitos objetos utilizados poderiam ser interpretados como documentações que descreviam e explicitavam o machismo, mais do que contestavam de fato a tradição patriarcal. Essa questão tornou-se um problema de difícil resolução, especialmente por apresentar-se numa era em que os artistas se preocupavam mais que nunca em transmitir uma mensagem inteligível para a sociedade.

Laura Cottingham esclarece o motivo das diferenças cruciais, porém inevitáveis, entre o que o artista pensava estar produzindo e o que era interpretado pelos espectadores: "Excetuando-se a arte que evita, em geral, a iconografia da representação feminina e especificamente a experiência feminina, toda enunciação cultural que busca exceder (ultrapassar) a epistemologia do ser feminino corre o risco de dar a volta em seu significado, de tornar-se exatamente o que pretende não ser."7

Dentre as técnicas e temáticas empregadas pela primeira geração de artistas feministas norte-americanas (décadas de 1970 e 1980), as que mais traziam interpretações ambíguas e geravam controversas eram as que abordavam o papel doméstico feminino e o corpo da mulher (principalmente através da nudez).

Segundo Cottingham, a forte presença do corpo feminino em fotografias ou em performances (geralmente aludindo às leis de reprodução, aborto, casamento, direitos homossexuais, estupro e outras violências de natureza sexual contra mulheres) se deve ao fato de que o corpo feminino simbolizava o que as mulheres eram (biologicamente) e aquilo que elas não eram (política e socialmente). O corpo, ao carregar simultaneamente a identidade e a "prisão" femininas, transformou-se em uma ferramenta ideal. No entanto, no âmbito da interpretação da obra, o nu feminino evocava cognitivamente o tema da sexualidade e pornografia (a mulher vista como objeto sexual), que era um domínio exclusivamente masculino.

O movimento feminista procurava ser isento de restrições formais e apresentava combinações de técnicas 
${ }^{8}$ Grande parte das obras de Barbara Kruger não possui título; é comum que autores se refiram a elas (principalmente à série dos anos 1980) tomando por título as frases inseridas nas imagens. Procederemos de igual maneira neste artigo.

${ }^{9}$ Texto original do pôster: "Apoie o aborto legal, o controle de natalidade e os direitos da mulher" e "No dia 26 de abril o supremo tribunal colocará em sessão o caso, através do qual a administração governamental de Bush espera conseguir reverter a decisão sobre o processo Roe versus Wade, que estabeleceu direitos básicos de aborto. Una-se a milhares de mulheres e homens em Washington D.C. no dia 9 de abril. Nós iremos mostrar que a maioria do povo americano apoia o direito de escolha das mulheres. Em Washington: Assembléia na Ellipse entre o Monumento de Washington e a White House às 10h00min; reunião no Capitol (sede do parlamento americano) às 13 h 30 min".

${ }^{10}$ Roe versus Wade foi um processo controverso e politicamente significante executado pela suprema corte dos Estados Unidos em 1973. Sua conclusão foi um marco importante nas decisões referentes ao aborto: a corte cedeu $\mathrm{o}$ direito ao aborto sem necessidade de que a mãe justificasse a razão da escolha, no entanto, foram estabelecidas restrições referentes ao tempo de gestação e à viabilidade de vida do feto fora do útero. A questão da legalização do aborto tornouse um debate nacional que gerou a divisão pro-roe (pró-escolha) e pro-wade (pró-vida). Em resposta à concessão do aborto como direito constitucional, muitos estados tentaram legalizar leis restringindo sua regularização, como a necessidade de consentimento dos pais no caso de menores de 18 anos, consentimento do casal etc. $\mathrm{O}$ presidente em mandato durante o processo (Nixon, 1969-1974) e os que o sucederam após a decisão da corte, até a data de diversas que variavam conforme a intenção do artista: era um movimento movido pela demanda de um novo conteúdo mais do que pela criação de um estilo próprio. Na primeira onda feminista, a pintura e outras técnicas mais tradicionais estavam presentes, por exemplo, na obra de Miriam Shapiro e Judy Chicago, porém em pequena escala. Destacavamse principalmente os meios recém-introduzidos no campo artístico, como a apropriação de fotografias e de objetos (nas obras de Barbara Kruger, Laurie Simmons, Annette Messager, Mary Kelley e Martha Rosler), a instalação (com contribuições de Judy Chicago e Miriam Shapiro), performances (Valie Export e Adrian Piper) e a fotografia (Nan Goldin e Cindy Sherman).

\section{Engajamentos políticos na obra de Barbara Kruger}

A sintonia da obra de Kruger com a prática feminista do período (protestos e manifestações) é explicitada por uma de suas obras mais famosas: Your body is a battleground, ${ }^{8}$ que, segundo a Broad Art Foundation (que possui os direitos da obra), era dotada de mais texto ${ }^{9}$ e consistia em um pôster para a marcha pro-choice (pró-escolha), referente ao processo Roe vs Wade (1973), que ocorreu dia 9 de abril de 1989 em Washington, D.C. ${ }^{10}$

Para a elaboração de Your body is a battleground, a artista apropria-se de uma fotografia em preto e branco, centralizada e frontal, de um rosto feminino, fotografia esta que foi provavelmente retirada de uma revista antiga. Trata-se da face de uma modelo, que se encontra dividida verticalmente ao meio através do recurso da negativização da metade direita da fotografia, o que cria uma linha divisória imaginária devido ao contraste. A fotografia é sobreposta por retângulos vermelhos horizontais que emolduram segmentos da frase "Your body is a battleground" (Seu corpo é um campo de batalha), escrita com a tipografia Futura Bold Italic em letras brancas.

Ao separar o rosto da modelo em duas partes com cores invertidas, a artista subverte o significado original da fotografia, pois cria uma dualidade na imagem que, sem a divisão, aludia à perfeição. A serigrafia é constituída por dois extremos opostos (o positivo e o negativo) que também estão presentes no texto: a impressão orgânica e natural que a palavra body (corpo) produz entra em conflito com o significado político da palavra battleground (campo de batalha). O estranhamento criado com a sugestão de uma intervenção do governo diretamente no corpo das mulheres está intimamente relacionado ao argumento feminista a 
execução da obra de Kruger, com exceção de Jimmy Carter (1977. 1981), manifestaram oposição à legalização do aborto nos termos de Roe v. Wade. Referimo-nos aqui a Gerald Ford (1974-1977), Ronald Reagan, (1981-1989) e George H. W. Bush, (1989-1993).

11 É praticamente impossível identificar a procedência das fotografias apropriadas por Barbara Kruger. Sabe-se que as imagens estavam originalmente presentes em mídias publicadas aproximadamente entre as décadas de 1940 até 1980 , no entanto Kruger jamais fornece mais informações sobre elas, como nomes e edições dos periódicos e datas precisas de publicação. Uma das únicas imagens cuja origem é conhecida é a que foi utilizada na obra It's a small world but not if you have to clean it (1990). Essa informação veio a público em função de um processo contra a artista aberto pelo fotógrafo Thomas Hoepker, que alegava violação dos direitos de reprodução da imagem da modelo Charlotte Dabney (feita por ele e publicada na revista Foto Prisma em torno de 1960). favor do aborto, que se baseia no direito de escolha da mulher e de decisões relativas a seu próprio corpo.

Pode-se dizer que a artista abordou o tema de modo a causar uma sensação inquietante que instiga seus espectadores a refletirem sobre as implicações da proibição do aborto e a manifestarem ou, no mínimo, repensarem suas opiniões e reivindicações. Ao exigir do público um posicionamento político ou social, Barbara Kruger tem a intenção de transformar o espectador passivo em um sujeito engajado ou, pelo menos, reflexivo, afinal é improvável que o espectador se relacione com a obra de maneira alienada.

No ano seguinte, em 1990, a artista aplicou o mesmo texto (your body is a battleground) sobre uma imagem fotográfica de um rosto feminino com expressão de desespero. A alteração na imagem, agora disposta horizontalmente e de forma retangular, não comprometeu o sentido da obra. A artista projetou a exposição dessa obra em um outdoor ironicamente localizado ao lado de outro que continha propaganda pro-life (pró-vida), no qual havia uma figura de um feto de oito meses de gestação e o texto: "Vivo e Crescendo: batimentos cardíacos, ondas cerebrais, impressões digitais, sente dor. Oito semanas no útero. Vote pró-vida 445-65083.

O fato de Your body is a battleground ter sido feita especificamente para a passeata pro-choice permite analisá-la também como instrumento político e conscientizador, e não apenas como objeto artístico. As obras de Kruger tendem a se distanciar do público restrito do universo artístico gerenciado por galerias de arte e museus, à medida que possuem uma mensagem direcionada à sociedade em geral e que pretendem aproximar a arte (sua utilidade e inteligibilidade) à vida cotidiana.

A relação que Kruger cria entre arte, política, filosofia e antropologia torna-se ainda mais evidente com a análise de We won't play nature to your culture, uma serigrafia fotográfica em preto e branco de um close da cabeça de uma mulher repousando sobre o chão, com os olhos encobertos por duas folhas de árvore. Sobreposta a essa imagem lê-se a frase "we won't play nature to your culture" (nós não atuaremos como natureza para a sua cultura). A origem da fotografia é desconhecida, no entanto, sabe-se que se trata de mais uma apropriação de imagem da mídia publicitária (jornais, revistas, comerciais etc.). ${ }^{11}$

Acerca da relação entre imagem e texto, pode-se dizer que esses elementos se relacionam de forma complementar, porém dual: a inserção das palavras we won't sugere uma manifestação contestadora que se opõe ao conteúdo da imagem, pois essa apresenta uma figura 
feminina em repouso, e não em uma atitude subversiva. Nota-se que a organização compositiva cria uma dualidade ou oposição entre as palavras nature (natureza) e culture (cultura), o que se deve ao fato de elas se encontrarem aumentadas e com as cores das letras e das tarjas invertidas entre si. O destaque dado a essas palavras enfatiza a dualidade que a artista pretende estabelecer entre o gênero feminino e o masculino, os quais são vinculados respectivamente à ideia de natureza e de cultura com a associação do pronome pessoal "nós" a um sujeito feminino e do pronome possessivo "sua" ao masculino.

Na obra analisada, o pronome we não abriga um referencial masculino, que geralmente se encontra em segundo plano, senão excluído. Isso ocorre devido a uma associação da primeira pessoa do plural à figura feminina, pois na obra em questão essa figura está visualmente vinculada ao conceito de natureza (devido à presença das folhas sobre seus olhos). Com a associação do gênero feminino ao pronome we, o referencial masculino aproximase naturalmente do pronome possessivo your, pois a artista estabelece uma oposição entre os gêneros implícita no emprego dos pronomes e no conteúdo da frase.

Ressalte-se que na maioria das obras de Kruger a atribuição de gênero se dá com a associação implícita dos pronomes "eu" e "nós" a um referente feminino, enquanto "tu" e "seu" são geralmente vinculados ao masculino (ainda assim, os espectadores se identificam intercaladamente com os dois extremos do discurso, independentemente de serem homens ou mulheres).

O fato de a artista não especificar os sujeitos aos quais os pronomes se referem permite ao espectador deslocar-se como referencial ora do pronome pessoal "eu" ou "nós", ora do "tu" ou "vocês". Esse deslocamento é possível porque, como caracterizado por Jakobson, os pronomes pessoais são embreantes (shifters) por pertencerem a uma categoria de signos linguísticos vazios que são momentaneamente preenchidos. Em uma conversa, por exemplo, os referentes dos pronomes "eu" e "fu" variam conforme se alternam os interlocutores.

Essa característica permite aos pronomes abrigar o espectador sem se referir especificamente a ele: trata-se de artifícios que se articulam cognitivamente conforme 0 espectador define o seu posicionamento individual no discurso (ainda que esse seja imperativo e impessoal, o uso do pronome permite que o observador se relacione de forma particular com o conteúdo expresso). A indução a um posicionamento específico é o aspecto que, segundo Craig Owens, confere corpo à obra. ${ }^{12}$ 
${ }^{13}$ OWENS, 1992. p. 191

14 ORTNER, 1996.

15 Todavia, O caráter universal atribuído à dominação masculina que aparece em seu texto de forma veemente, foi criticado após a publicação do referido artigo. Em entrevista, a autora esclareceu esse aspecto de seu texto: "A afirmação sobre a dominação masculina universal veio de uma conversa distinta. Naquele período do feminismo, muita gente escrevia sobre todo tipo de tema e mesmo sobre coisas que não conheciam bem. [... Revisei a bibliografia etnográfica e não pareciam existir nem mesmo sociedades igualitárias. Foi daí que veio esta forte afirmação de que em todas as culturas conhecidas os homens são, em certa medida o primeiro sexo, se não necessariamente dominantes no sentido político, preeminentes no sentido carismático e do prestígio, ou em ambos. Esse foi o contexto do artigo" (trecho retirado da entrevista com Sherry Ortner elaborada por pesquisadores do núcleo de estudos de gênero Pagu/Unicamp, disponível em http://www.scielo.br/ scielo.php?pid=S0104-83332006 $000200016 \&$ script $=$ sci_arttext.
Para Owens, essa obra faz uma crítica ao estereotipo da imagem da mulher na sociedade patriarcal ocidental, pois a figura feminina presente na fotografia não é considerada parte integrante da cultura; encontra-se fora dela, em um estado de natureza (ironicamente representado pelas folhas colocadas sobre os seus olhos). Sua análise também ressalta a existência de "uma lógica binária que divide o ser social em duas metades desiguais de forma a submeter uma à outra". ${ }^{13}$ Entende-se, assim, que se trata de uma questão relacional, em que um lado depende e interfere no posicionamento do outro para existir, e que a natureza, nesse contexto, é dominada pela cultura patriarcal.

Com o emprego da frase we won't play nature to your culture Kruger aborda e evoca uma questão estudada por diversas feministas, que consiste na análise da diferença relacional (de superioridade e inferioridade) de gênero a partir da associação da figura feminina à natureza e, consequentemente, da aproximação do masculino à cultura.

Podemos relacionar essa obra à análise empreendida por Sherry B. Ortner no artigo "Is female to male as nature is to culture?" (A mulher está para o homem assim como a natureza está para a cultura?), publicado no mesmo período em que Kruger produziu Untitled (we won't play nature to your culture). ${ }^{14}$

Em seu texto, a autora aponta fatores de ordem fisiológica, da psique da mulher e de seus papéis sociais, que induzem à associação da figura feminina à natureza. Ortner estabelece que grande parte dessa aproximação, que na verdade caracteriza-se mais como uma afinidade da mulher com a natureza (em oposição a uma particularidade generalizante), é determinada por funções específicas do corpo feminino, que condicionam a psicologia da mulher a questões referentes à vida em um sentido mais instintivo ou natural, como a maternidade, e menos cultural. As funções do corpo feminino, segundo a autora, também delimitam a atuação das mulheres como sujeitos sociais, de forma que elas exercem papéis considerados mais baixos na ordem dos processos sociais. É importante mencionar que a análise de Sherry Ortner não visa oficializar ou justificar a relação do gênero feminino com a natureza e do masculino com a cultura, mas busca interpretar as causas de um fenômeno que ela julga ser recorrente em todas as comunidades. ${ }^{15}$

Na realidade, a pesquisa de Sherry Ortner rejeita o determinismo biológico e a teoria de que a genética masculina carrega naturalmente a dominância do sexo na espécie, pois tal hipótese possui resultados e respostas antropologicamente insatisfatórios. Segundo Ortner, apesar de os fatores biológicos não serem irrelevantes e de as 
${ }^{16}$ ORTNER, 1996, p. 25.

7 ORTNER, 1996, p. 33: "As unidades domésticas são aliadas umas às outras através de ratificações de regras que estão logicamente, em um nível mais elevado que as próprias unidades; isso cria uma unidade emergente - a sociedade - que está logicamente em um nível mais elevado que as unidades domésticas, das quais ela é composta."

18 ORTNER, 1996, p. 33. mulheres e homens serem diferentes, a diferença relacional deve ser compreendida dentro de um sistema de valores definidos culturalmente.

Ortner procura ainda esclarecer o motivo pelo qual as associações da figura feminina à natureza e da figura masculina à cultura engendram uma relação de poder e dominância entre os gêneros: a submissão ou inferioridade atribuída ao feminino (à natureza) com relação ao masculino (entende-se, cultura) está vinculada ao fato de que a cultura é percebida como uma transcendência da natureza, o que estabeleceria uma relação de superioridade e domínio para com ela. Logo, as respectivas associações dos gêneros feminino e masculino aos domínios naturais e culturais caracterizam um sistema de ordem binária, interativo e hierárquico. "Toda cultura, ou, genericamente, 'cultura', é engajada no processo de gerar e sustentar sistemas de significados (símbolos, artefatos etc.), através dos quais a humanidade transcende os atributos da existência natural, manipula-os para seus próprios propósitos, controla-os em beneficio de seu interesse", afirma a autora. ${ }^{16}$

Com relação à fisiologia feminina, Sherry Ortner analisa trechos de $O$ segundo sexo para introduzir o conceito de que muitas áreas e processos do corpo feminino possuem funções que aparentemente não priorizam a saúde e a estabilidade do indivíduo: a menstruação e diversos aspectos do processo de dar à luz, por exemplo, podem ser dolorosos e interferir nas atividades sociais e na saúde da mulher. $O$ aprisionamento da mulher a funções reprodutivas revela a contribuição da fisiologia para o fortalecimento da suposta associação da figura feminina com a natureza, bem como do homem com a cultura, devido ao fato de suas funções se diversificarem, serem mais exteriorizadas e, portanto, libertadoras.

A oposição entre o doméstico (íntimo/privado) e o público provoca uma tomada de posicionamento que gera exclusão e inclusão nesses domínios. O pertencer da mulher majoritariamente ao âmbito doméstico (atribuído à maternidade, mais especificamente ao processo de lactação) leva-nos a associá-la a um grupo de ordem social inferior dentro da organização cultural e social. ${ }^{17}$

Para Sherry Ortner, "Os homens não se identificam somente com a cultura, no âmbito de toda a criatividade humana, em oposição à natureza; eles se identificam em particular com a cultura em um sentido tradicional (oldfashioned) dos mais finos e altos aspectos do pensamento humano - arte, religião, direito etc". ${ }^{18}$ Partindo dessa ideia, é possível traçar um paralelo entre We won't play nature to your culture e a obra Do women have to be naked to get into the Metropolitan Museum? (1989), elaborada pelo grupo 
anônimo Guerrilla Girls (1985), pois ambas estabelecem uma referência à questão da aproximação do gênero feminino com a natureza e do masculino com a cultura.

Trata-se de um pôster elaborado para a Public ArtFund de Nova York (que rejeitou a proposta), contendo o texto "As mulheres precisam estar nuas para pertencerem ao Museu Metropolitan? Menos de $5 \%$ dos artistas nas seções de Arte Moderna são mulheres, mas $85 \%$ dos nus são femininos". Ao lado esquerdo dos dados expostos, vê-se o recorte de uma figura nua retirada do célebre quadro Odalisca de Ingres, que aparece com o rosto encoberto por uma máscara de gorila (característica do grupo Guerrilla Girls).

O conteúdo dessa obra aproxima-se da discussão levantada por Sherry Ortner a partir do momento em que se entende que a ausência de mulheres artistas em mostras de arte moderna reflete seu distanciamento da alta cultura, que é dominada e administrada pelo gênero masculino. Na obra das Guerrilla Girls, a interpretação do número alto de frequência dos nus femininos na arte, com relação aos masculinos, permite apreender a mulher como uma espécie de objeto culturalmente adormecido, alvo do olhar contemplativo e isenta de participação como sujeito-social ou agente atuante na cultura moderna e contemporânea.

Essa temática, que surgiu acompanhada de forte embasamento teórico do campo da antropologia e filosofia da década de 1970, foi abordada por Judy Chicago (pioneira na arte feminista) na obra Dinner Party, produzida entre 1974 e 1979 e que desde 2007 encontra-se em exibição permanente no Brooklyn Museum de Nova York.

Trata-se de uma instalação composta por uma mesa de formato triangular que delimita um triângulo interno vazado, dentro do qual se vê o chão formado por azulejos de porcelana nos quais foram escritos os nomes de mais de 999 mulheres que contribuíram de forma notável em diferentes campos da cultura. Ao longo do comprimento das bordas do triângulo, foram colocadas 39 toalhas de mesa, que delimitam um assento individual designado a mulheres místicas e historicamente importantes (artistas, escritoras, poetizas etc) que possuem seus nomes, entre outros símbolos que aludem às suas vidas e conquistas, bordados nas toalhas de mesa. Cada fragmento contém um jogo de mesa personalizado, que inclui uma taça de cerâmica, talheres e um prato, em cima do qual se vê uma escultura cerâmica cujo formato se assemelha à parte externa do órgão genital feminino (vulva e lábios). Os materiais usados na elaboração dessa obra (cerâmica, pintura de porcelana e bordado) são propositadamente eleitos por estarem associados ao artesanato feminino (arte doméstica). 
${ }^{19}$ As contribuições mais influentes dessas autoras são From the Center: Feminist Essays on Women's Art (1976), de Lucy Lippard; Framing Feminism: Art \& the Women's Movement (197085), de Griselda Pollock; e Why Have There Been No Great Women Artists? (1971), de Linda Nochlin.

${ }^{20}$ Linda NOCHLIN, 2007.

${ }^{21}$ Griselda Pollock afirma que a consideração de mulheres artistas e de suas experiências promoveria mudanças de paradigmas na historia da arte e propõe, assim uma revisão feminista da disciplina.
De forma geral a obra evoca a dominação masculina da cultura sem explicitá-la: a intenção de Judy Chicago, ao realizar Dinner Party, era prestar uma homenagem às mulheres cujos trabalhos e méritos eram notáveis, mas que não foram devidamente reconhecidos pelo fato de seus autores serem mulheres. Essa obra permite uma interpretação centrada também na ausência da mulher, pois se trata de uma mesa posta, no entanto, não ocupada: a presença simbólica das mulheres homenageadas subentende a sua ausência ou exclusão da construção cultural.

Essa temática, que se consolida na arte feminista dos anos 1980 em forma de crítica à ausência feminina em outras áreas da alta cultura (literatura, cinema, política etc), está fundamentada em pesquisas e textos de algumas teóricas adeptas de ideologias feministas influentes no campo artístico como Lucy Lippard, Cindy Nemser, Linda Nochlin e Griselda Pollock. ${ }^{19}$ Nas décadas de 1970 a 1980 essas teóricas lideraram discussões e protestos relacionados à discriminação contra mulheres artistas em exposições, utilizando como base, tal qual o grupo Guerrilla Girls, os dados relacionados ao número de artistas mulheres aceitas em mostras de museus e galerias.

Em 1970, a constatação da pequena participação de mulheres artistas em exposições levantou questões como "por que não existiram grandes mulheres artistas?", que, na análise de Linda Nochlin, se deve ao fato de conceitos como "gênio", "maestria" e "talento" terem sido elaborados e aplicados exclusivamente aos homens, no passado. ${ }^{20}$ Esse e outros questionamentos propiciaram uma abordagem mais ampla, discutindo, inclusive, a possibilidade da existência de uma arte essencialmente feminina e como se efetuaria a introdução da mulher na história da arte. ${ }^{21}$

A consciência da exclusão feminina do mercado artístico levou as curadoras e críticas a tomarem medidas que procurassem reverter tal panorama, que, até então, não encorajava as mulheres artistas a produzir. Para tanto, foram organizadas uma série de exposições que priorizavam a arte feita por mulheres, como, por exemplo, a Aprox. 7.500, elaborada por Lucy Lippard, e a Mostra de Mulheres Artistas de 1550 a 1950, organizada por Linda Nochlin e Ann Sutherland, em Los Angeles no final da década de 1970.

Esse primeiro cenário de abertura contribuiu para a propagação de novas iniciativas de inclusão de mulheres artistas em mostras de museus e galerias e para a criação de fundos e programas de faculdades (como o Feminist Art Program, criado por Judy Chicago na CalArts - Universidade da Califórnia) que incentivavam a participação feminina nas artes visuais.

A arte feminista iniciada nos anos 1970 teve continuidade em sintonia com o contexto histórico, político e 
social do movimento das mulheres. As manifestações artísticas acompanharam as mudanças e reivindicações de momentos específicos e se transformaram à medida que o feminismo tomou novas formas.

Apesar de algumas artistas produzirem atualmente arte feminista com fortes referências ao que se produziu nas décadas de 1970 e 1980 nos Estados Unidos (como, por exemplo, a artista basca Ana Laura Alaéz, que se apropria de uma estética pop e utiliza objetos como o batom para se referir ao universo feminino), no final da década 1980 o movimento artístico feminista se fragmentou em vertentes que dialogavam com teorias pós-feministas com base, por exemplo, nos textos de Judith Butler, que analisa a construção (e desconstrução) de gênero e da sexualidade. Essa discussão proporcionou um adensamento do campo teórico que abarca hoje uma exploração artística da teoria queer (presente nas obras de Sarah Lucas e Linda Benglis) e do post-porno, entre outros temas. Outra transformação que se reestrutura e ganha nova linguagem é a representação feminina, que atualmente é abordada de uma forma mais libertadora e desvinculada dos padrões estéticos baseados em valores sexistas, como se observa em algumas obras de Pipilotti Rist.

Para concluir gostaríamos de ressaltar a importância do caráter contestador da obra de Barbara Kruger, que aborda de forma sintética e pontual questões amplas e densas, transformando-as em símbolos facilmente inteligíveis a um público amplo. Craig Owens aponta que muitos artistas denunciam a arbitrariedade dos estereótipos como algo extrínseco ao sujeito, imposto pela sociedade e que pode facilmente ser rejeitado. Barbara Kruger aborda o tema entendendo-o como um instrumento de poder: parte do pressuposto de que os estereótipos constituem parte integral dos processos sociais do relacionamento humano, como incorporação, exclusão e dominação. A artista serve-se de estereótipos como recursos, com forte base teórica que advém do campo da filosofia, para gerar reflexões e indagações socialmente importantes para a conscientização e mobilização em torno de causas ainda presentes na sociedade atual como a discriminação.

\section{Referências bibliográficas}

COTIINGHAM, Laura. Seeing through the Seventies - Essays on Feminism and Art. London: $\mathrm{G}+\mathrm{B}$ Arts International Imprint, 2000.

DE BEAUVOIR, Simone. O segundo sexo. Lisboa: Edição Bertrand. 1949. v. 2.

GABLIK, Suzi. Has Modernism Failed? 2nd ed. London: Thames \& Hudson, 2004. 
LIPPARD, Lucy R. The Pink Glass Swan: Selected Feminist Essays on Art. New York: New York Press, 1995.

NOCHLIN, Linda. "Why Have There Been No Great Women Artists?" In: REIMAN, Karen C.; SÁENZ, Inda. Crítica feminista en la teoría e historia del arte. México: Universidad lberoamericana, 2007. p. 17-43.

ORTNER, Sherry B. Making Gender - The Politics and Erotics of Culture. Boston: Beacon Press, 1996.

OWENS, Craig. Beyond Recognition: Representation, Power and Culture. Los Angeles: University of California Press, 1992.

[Recebido em 8 de março de 2010 e aceito para publicação em 14 de setembro de 2010]

\begin{abstract}
Artistic Activism: Political Awareness and Gender Issues in Barbara Kruger's Work. Abstract: The present article introduces and contextualizes early feminist artworks which emerged in the late 1960's up to the 1980's. It analyzes the historical circumstances which linked the artistic and social spheres, as well as the aesthetic and formal problems that came along with the artistic activist practice and its reception as a movement. The analysis will be based on the work of the North-American artist Barbara Kruger, who has produced fundamental pieces which consolidate feminist art. Kruger's work has a critical approach towards a large variety of subjects regarding women (violence, abortion, identity, social roles, aesthetics). The content of her work is engaged with important social matters and with the political scene at the period of its production, and it also bears a direct relation with the feminist theories of that period, reasons which allow for an analysis of both the artistic and the social-political contexts.

Key Words: Barbara Kruger; Artistic Activism; Feminism; Contemporary Art.
\end{abstract}

